\title{
ORIGINAL ARTICLE \\ Posterior circulation infarction in patients with traumatic cervical spinal cord injury and its relationship to vertebral artery injury
}

\author{
LL de Heredia ${ }^{1}$, M Belci ${ }^{2}$, D Briley ${ }^{3}$, RJ Hughes ${ }^{1}$, B McNeillis $^{1}$, TM Meagher ${ }^{1}$, S Yanny ${ }^{1}$ and D McKean ${ }^{1}$
}

Study design: Prospective study.

Objective: To ascertain the prevalence of posterior circulation stroke in traumatic chronic spinal cord injured (SCl) patients and associated traumatic vertebral artery injuries (VAI).

Methods: All adult patients with cervical SCI and American Spinal Injury Association Impairment Scale (AIS) grade A or B referred for follow-up magnetic resonance imaging of their spinal cord were invited to take part in the study between January 2010 and December 2012 at the National Spinal Injury Centre. Two additional sequences were added to the existing imaging protocol to evaluate the brain and vertebral arteries.

Results: Ninety-eight patients were recruited. All imaging were analysed independently by three consultant radiologists. Posterior circulation infarcts were noted in seven (7\%) patients. Significant VAI was noted in 13 patients (13\%) with 10 occlusions and 3 with high-grade stenosis. However, only one patient had co-existent posterior circulation infarct and significant VAl.

Conclusion: There is an increased prevalence of posterior circulation infarction in SCl patients. The relationship with associated traumatic VAI requires further investigation.

Spinal Cord (2015) 53, 125-129; doi:10.1038/sc.2014.145; published online 2 September 2014

\section{INTRODUCTION}

Vertebral artery injuries (VAI), which includes occlusion, dissection, intimal tear, stenosis and pseudoaneurysm formation, are welldocumented sequelae of blunt traumatic cervical injury in both neurologically intact and patients with spinal cord injury (SCI). ${ }^{1-3}$ Rates of VAI associated with cervical spinal trauma vary significantly with the incidence ranging from 3 to $88 \%$ in the literature. Prospective studies suggest rates in the range of $17-27 \%^{4-8}$ with a fatal outcome reported in rare cases. ${ }^{9}$

Evaluation of vertebral arteries has become increasingly feasible with modern imaging systems. Almost all patients with acute SCI will undergo multidetector computer tomography (CT) and magnetic resonance imaging. Inclusion of contrast in the $\mathrm{CT}$ study to procure CT angiography or time of flight (TOF) magnetic resonance angiography (MRA) of the carotid and extracranial vertebral arteries will add little time to imaging assessment and, although neither technique is as sensitive as catheter angiography, they will identify the majority of serious arterial injuries. ${ }^{8}$

There are conflicting and limited reports as to the association of posterior cerebrovascular embolic strokes with VAI; one series did not find any cases of stroke in a cohort of 64 patients with VAI assessed with brain magnetic resonance imaging ${ }^{4}$ whereas another reported a $24 \%$ incidence of stroke with a mortality rate of $8 \%{ }^{1}$

In the context of SCI, evaluation of any co-existing brain infarct is difficult. Posterior circulation infarction can be subtle in presentation, and the presence of established cervical cord injury profoundly limits clinical examination making imaging critical in the detection of and diagnosis of cerebrovascular events in SCI patients.

The identification of SCI patients at risk of posterior circulation infarct secondary to VAI is no longer one simply of academic interest. The development of successful vertebral artery intervention in the trauma setting ${ }^{5,6,10}$ means it may now be technically feasible to treat VAI if this is shown to improve patient outcome, such as decreasing the risk of subsequent posterior circulation stroke.

This study examines the point prevalence of posterior circulation infarction in SCI patients and its association with persistent VAI.

\section{MATERIALS AND METHODS}

Adult patients with a previous traumatic cervical spinal damage at least 6 months since injury with an American Spinal Injury Association impairment scale (AIS) grade A or B attending for follow-up imaging of their cervical cord at the National Spinal Injury Centre were invited to participate in this study between January 2010 and December 2012. The National Spinal Injury Centre research review board approved this prospective study and favorable ethics opinion was granted in March 2009 from Milton Keynes Research Ethics Committee (REC ref. no. 09/H0603/6). Written informed consent was obtained from each patient.

In addition to standard spine magnetic resonance imaging sequences, all patients had additional two or three dimensional TOF MRA of carotids and vertebral arteries for the detection of vertebral artery stenosis and axial

${ }^{1}$ Department of Radiology, Stoke Mandeville Hospital, Buckinghamshire Healthcare NHS Trust, Ayelsbury, UK; ${ }^{2}$ National Spinal Injuries Centre, Stoke Mandeville Hospital, Buckinghamshire Healthcare NHS Trust, Ayelsbury, UK and ${ }^{3}$ Department of Neurology, Stoke Mandeville Hospital, Buckinghamshire Healthcare NHS Trust, Ayelsbury, UK Correspondence: Dr D McKean, Radiology Department, National Spinal Injuries Centre, Stoke Mandeville Hospital, Buckinghamshire Healthcare NHS Trust, Mandeville Road National Spinal Injuries Centre, Ayelsbury, Buckinghamshire HP218AL, UK.

E-mail: drdavidmckean@gmail.com

Received 22 January 2014; revised 22 June 2014; accepted 28 July 2014; published online 2 September 2014 
T2-weighted fast spin echo brain sequence for the detection of posterior circulation strokes.

Patients were imaged by using a 1.5-T MR scanner Symphony System (Siemens, Erlangen, Germany) and an eight-channel neurovascular phasedarray coil. The TOF MRA imaging parameters were as follows: $50^{\circ}$ flip angle, $256 \times 163$ matrix, $200 \times 150$ field of view, 64 slices, $3 \mathrm{~mm}$ section thickness, overlap $1 \mathrm{~mm}$, TR 27, TE6.59 and acquisition time of $3 \mathrm{~min} 55 \mathrm{~s}$. The magnetic

Table 1 Demographic data of patients with vertebral artery injury

\begin{tabular}{|c|c|}
\hline $\mathrm{N}=13$ & $\%(n)$ \\
\hline Male & $77(10)$ \\
\hline Female & $33(3)$ \\
\hline Mean age & $47(25-78)$ \\
\hline Spinal fixation & $38(5)$ \\
\hline AIS A & $77(10)$ \\
\hline AIS B & $33(3)$ \\
\hline \multicolumn{2}{|c|}{ Vertebral artery grading } \\
\hline \multicolumn{2}{|c|}{$\mathrm{N}=196$ vertebral arteries in 98 patients } \\
\hline Grade 0 & $0.5(1)$ \\
\hline Grade 1 & 91 (179) \\
\hline Grade 2 & $1.5(3)$ \\
\hline Grade 3 & $1.5(3)$ \\
\hline Grade 4 & $5(10)$ \\
\hline \multicolumn{2}{|c|}{ Vertebral artery affected } \\
\hline Left & $33(3)$ \\
\hline Right & $77(10)$ \\
\hline \multicolumn{2}{|c|}{ Neurologic cervical level of injury } \\
\hline $\mathrm{C} 4$ & $15(2)$ \\
\hline C5 & $54(7)$ \\
\hline C6 & $15(2)$ \\
\hline $\mathrm{C7}$ & $15(2)$ \\
\hline
\end{tabular}

Abbreviation: AIS, American Spinal Injury Association Impairment Scale.
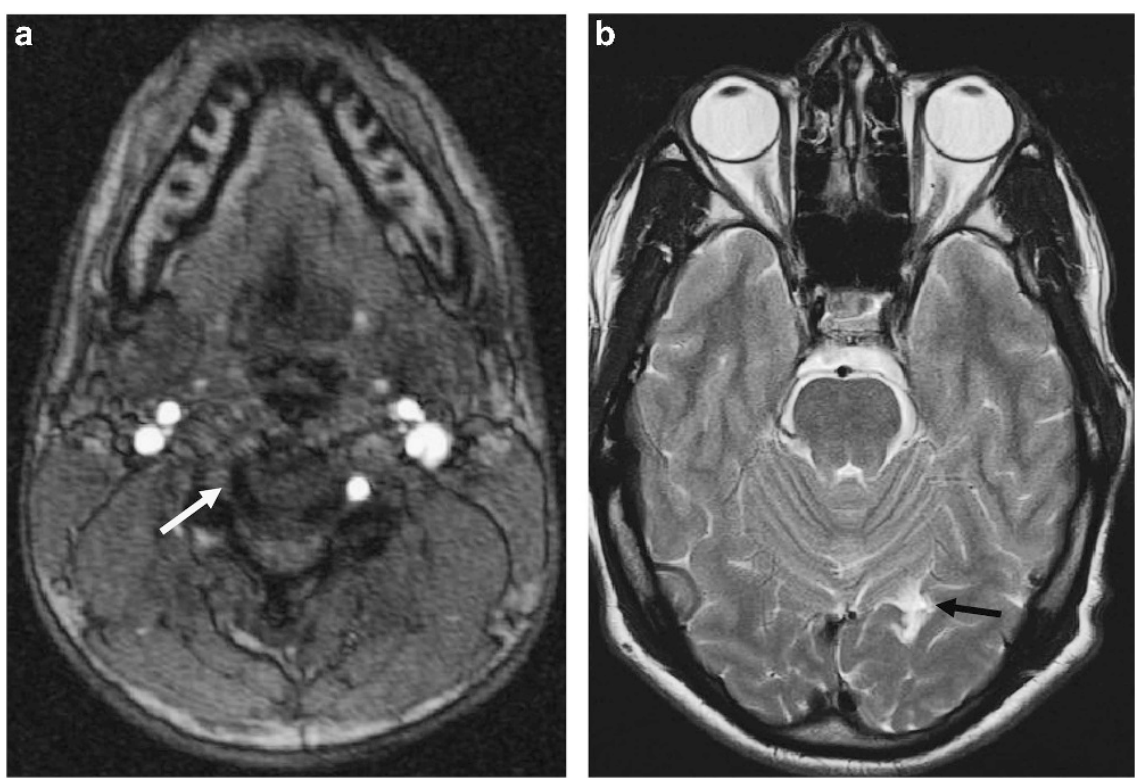

Figure 1 Occluded vertebral artery. A 37-year-old patient who sustained a C7 AIS A spinal cord injury. (a) Axial images from a two dimensional TOF acquisition show absence of flow (arrow) in the V2 segment of the right vertebral artery (Grade 4). (b) Axial T2-weighted image demonstrates a wellcircumscribed focus of high signal within the left occipital lobe typical of established posterior circulation infarct (arrow). 

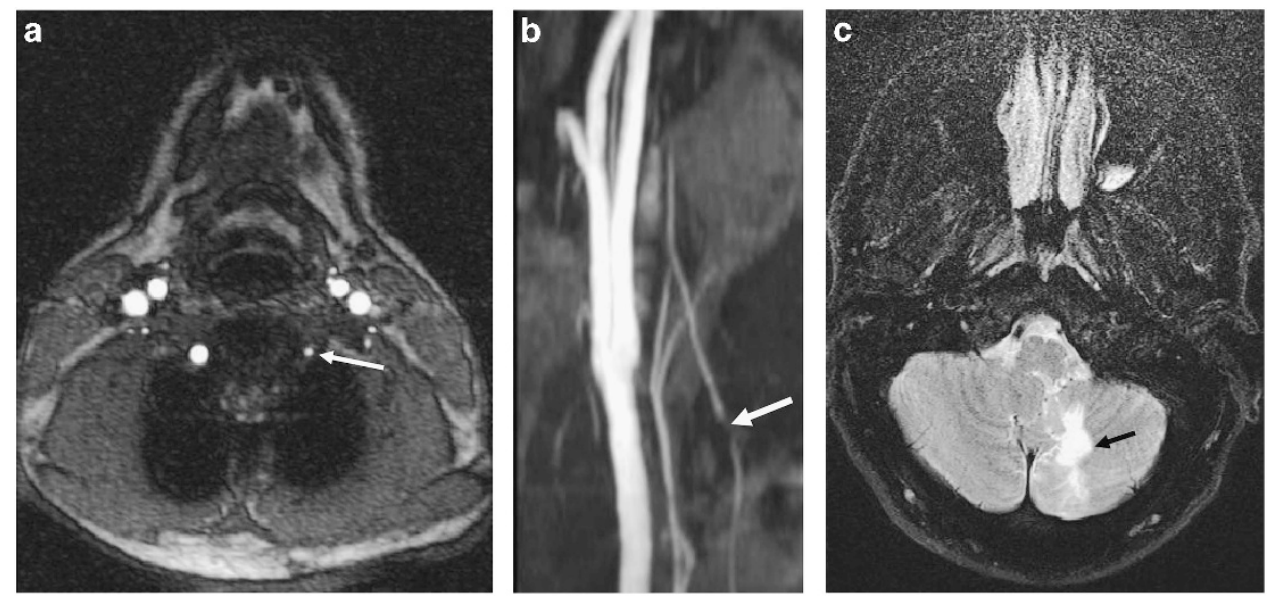

Figure 2 Hypoplastic vertebral artery. A 31-year-old patient who sustained a C6 AIS A spinal cord injury. (a) Axial image (anterior view) from a two dimensional TOF acquisition shows a hypoplastic left vertebral artery (arrow) (Grade 2). (b) MIP image (anterior view) from a two dimensional TOF acquisition shows absence of signal in the expected course of the left vertebral artery (arrow). (c) Axial T2-weighted image demonstrates a wellcircumscribed focus of high signal within the left cerebellar hemisphere in keeping with previous posterior circulation infarct (arrow).
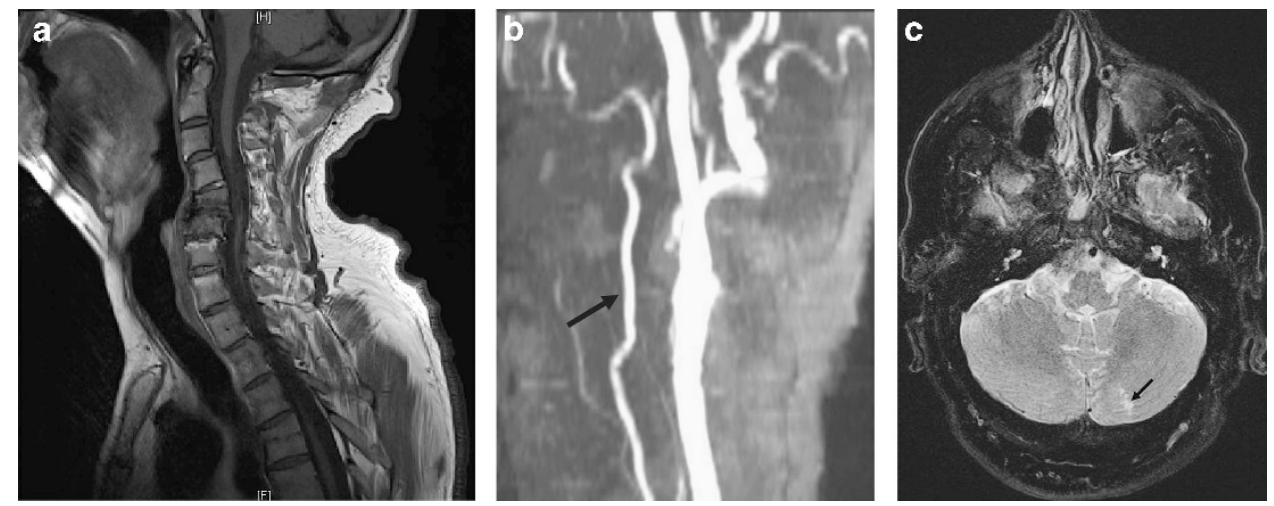

Figure 3 Normal vertebral artery. A 55-year-old man with long-standing cervical fracture of C5-6 AIS A. (a) Sagittal T1-weighted image demonstrates old compression fracture of C5 with cord atrophy. (b) TOF MRA with normal vertebral artery (arrow) (Grade 1). (c) Axial T2-weighted image demonstrates a wellcircumscribed, hyperintense focus (arrow) within the left cerebellar hemisphere in keeping with previous posterior circulation infarct.

The distribution of cervical fracture levels associated with VAI was C4 (15\%), C5 (55\%), C6 (15\%) and C7 (15\%). The interobserver Kappa score was 0.9 for the grading of vertebral arteries.

The prevalence of posterior circulation stroke was $7 \%(n=7)$ with an interobserver Kappa score of 0.85 . One of these seven patients had suffered detectable neurological deterioration, changing the AIS grade from B to A. All the other patients in this trial remained clinically and neurologically stable. Of the seven patients with posterior circulation infarction, one had an occluded vertebral (grade 4), one had a hypoplastic vertebral artery (grade 2) and the remainder were normal (see Figures 1-3). In the posterior circulation stroke group, the mean age was 46 (range $31-72$ years), $71 \%$ were men $(n=5)$ and $86 \%$ were AIS A $(n=6)$ (Table 2).

Incidental findings included one patient with right temporal gliosis attributed to brain trauma and one with anterior circulation stroke.

\section{DISCUSSION}

This study demonstrates that SCI patients are at significantly higher risk of posterior circulation stroke compared with an age-matched normal population (Table 3 ) and have a high prevalence of VAI.
Although the prevalence of posterior circulation stroke in this series $(7 \%)$ is comparable with the global stroke risk found in a recent study of the general population, ${ }^{11}$ our patients are from a younger cohort. In addition, the vast majority of infarcts we report are in the posterior circulation territory in contrast to the predominance of supratentorial and anterior circulation strokes detected by MR in previous studies looking at clinically silent infarcts. ${ }^{11,12}$ These findings make the history of significant cervical trauma in our patients likely to be relevant to the aetiology of their cerebrovascular events ${ }^{11,13}$ (Table 3).

The prevalence of significant VAI in our group (13\%) was comparable with previous studies. ${ }^{4}$ The mechanism and timing of these posterior circulation infarcts in SCI patients remain unclear. It is probable that the cerebrovascular insult occurs at the time of acute injury secondary to vertebral artery transection or occlusion. However, we found no clear association between persistent VAI occlusion and posterior circulation stroke with only one patient with a vertebral artery occlusion demonstrating a posterior circulation stroke.

It may be that the cerebrovascular insult occurs at the time of acute injury secondary to vertebral artery transection or occlusion. 
However, no association between persistent VAI occlusion and posterior circulation stroke on follow-up imaging was seen in our study.

It may also be possible that the embolic episodes follow recanalisation of VAI in the post-traumatic period resulting in distal infarction. This may account for infarcts that have been clinically detected in the recovery period following acute spinal injury. ${ }^{14}$

This temporal relationship is an important consideration with respect to potential vertebral artery intervention. If infarction occurs at the time of injury, intervention will be of limited benefit. However, if infarction is a subacute phenomenon, there may be a rationale for careful assessment and intervention.

Finally, it may be that there is no relationship between VAI and posterior circulation stroke in SCI patients and that these infarcts are secondary to patient immobility. However, all SCI patients in our cohort have routinely received 6 months anticoagulation therapy post injury. In addition, the predominance of posterior circulation infarcts

\section{Table 2 Demographic data of patients with posterior circulation} stroke

\begin{tabular}{ll}
\hline $\mathrm{N}=7$ & $\%(\mathrm{n})$ \\
\hline Patients & \\
Male & $71(5)$ \\
Female & $29(2)$ \\
Mean age & $46(31-72)$ \\
Spinal fixation & $43(3)$ \\
Left & $57(4)$ \\
Right & $43(3)$ \\
AIS A & $86(6)$ \\
AIS B & $14(1)$ \\
& \\
Vertebral artery grading & \\
Grade 1 & $72(5)$ \\
Grade 2 & $14(1)$ \\
Grade 4 & $14(1)$ \\
Neurologic cervical level of injury & \\
C4 & \\
C5 & $29(2)$ \\
C6 & $14(1)$ \\
C7 & $43(3)$ \\
\hline
\end{tabular}

Abbreviation: AIS, American Spinal Injury Association Impairment Scale. and relative absence of supratentorial infarcts makes systemic embolic events a less likely hypothesis.

The detected rate of VAI will depend on the imaging technique used in assessment and the temporal relationship to the acute injury. Using catheter angiography, intimal tears and low-grade stenosis may be clearly evident and rates of detected injury correspondingly higher. ${ }^{1,5}$ The majority of studies evaluating VAI in the context of blunt trauma in the last decade have used TOF MRA, which is rapid and non-invasive. ${ }^{7-9}$ It is adequate to evaluate occlusion and highgrade stenosis but is limited in assessment of intimal injury and even pseudoaneurysm formation. ${ }^{15}$ Multidetector CT continues to improve in accuracy and currently its ability to assess VAI lies somewhere between catheter angiography and TOF MRA. ${ }^{16}$

Many previous studies have examined VAI in the context of acute or subacute trauma. A single study ${ }^{4}$ looked at follow-up imaging and noted recanalisation in previously occluded arteries. In another study, normalisation of the previously injured vertebral artery appearance was observed by the time of repeat imaging examination. ${ }^{17}$ This may explain the relatively lower rates of VAI in our study (13\%) compared with other published series. ${ }^{1,2,7}$ Our data may be consistent with the hypothesis that injuries which result in vertebral artery transection may in fact be protective for posterior circulation infarction, if the collateral circulation is sufficient to prevent an acute stroke, by preventing later embolic events at the time of recanalisation. However, further studies will be required to investigate this further.

Our series contrasts with the absence of stroke reported by Taneichi ${ }^{4}$, in a cohort of 64 patients with cervical fractures without cord injury, where the identified VAI rate was a similar $17 \%$. Torina et al. ${ }^{3}$ observed that VAI was more common with more severe SCI with increased rates in AIS A/B injured patients over AIS C/D graded injuries.

The grading of stenosis used in our study includes description of hypoplastic vertebral artery. This is a well-described often incidental finding in up to $10 \%$ of adult population ${ }^{18}$ but there is a risk in differentiating an incidental hypoplastic artery and a long dissection. We judged that if the V1 and V3 segments were uniformly narrow, dissection was unlikely. We have proposed a new simple vertebral artery grading system rather than as previously described by Biffl et al. ${ }^{19}$ as this pertained to catheter angiography: TOF MRA is not adequate to comment on intimal tears, minor thrombus or fistula formation.

A survey of current practice ${ }^{20}$ indicated a variable approach to treatment of both carotid and VAI following trauma including anti-coagulation, anti-platelet therapy, combined anticoagulation

Table 3 Posterior circulation stroke in the normal asymptomatic population compared with this study

\begin{tabular}{|c|c|c|c|c|c|}
\hline & $<45 y e a r s$ & $45-59$ years & $60-74$ years & 75-97 years & Total \\
\hline $\begin{array}{l}\text { Our study (mean age, } 46 \text { years; } \\
\text { range } 18-82 \text { ) }\end{array}$ & $3(6 \%, n=48)$ & $2(7 \%, n=27)$ & $2(10 \%, n=21)$ & $0(n=2)$ & $7(7 \%, n=98)$ \\
\hline $\begin{array}{l}\text { Vernooij et al. }{ }^{11} \\
\text { (mean age, } 63.3 \text { years; range, 45.7-96.7) }\end{array}$ & - & $30(4 \%, n=750)$ & $68(6.8 \%, n=993)$ & $47(18.3 \%, n=257)$ & $145(7.2 \%, n=2000)$ \\
\hline $\begin{array}{l}\text { Compter et al. }{ }^{13} \\
\text { (mean age, } 60 \text { years; range 52-68) }\end{array}$ & & & & & $\begin{array}{c}\text { No VA stenosis } 12(<0.1 \%, n=3435) . \\
\text { With asymptomatic VA stenosis } \\
5(0.4 \%, n=282)\end{array}$ \\
\hline $\begin{array}{l}\text { Katzman et al. }{ }^{21} \\
\text { (mean age, } 30.6 \text { years; range } 3-83 \text { ) }\end{array}$ & & & & & $3(0.3 \%, n=1000)$ \\
\hline
\end{tabular}

Abbreviation: VA, vertebral artery. 
and anti-platelet or stent placement. Although this study indicated a preference for anticoagulation alone, clinicians used all available options in practice. Clinicians were aware of the risk ischemic stroke and the detection of significant stenosis or vessel occlusion would be likely to change patient management significantly.

There are limitations to this study. The patient cohort is not randomised, is symptomatic, and limited to AIS A and B cord injury. The vertebral artery assessment method was TOF, both two and three dimensional, which carry significant constraints in detecting the spectrum of subtle VAI, including intimal tears.

Despite these limitations, the data indicate that in the context of blunt cervical trauma with cord injury, there is a significant risk of posterior circulation infarction. Our findings highlight the need for further research including both the early and late phase of injury to establish the temporal relationship between infarction, acute cervical blunt trauma and associated arterial injury. Clarification of both the absolute stroke risk and underlying mechanism is necessary to justify any potential therapeutic intervention that may also carry significant risk. Inclusion of CT angiography and MRA into routine protocols may be advocated in the acute and subacute period when assessing the cervical spine to detect associated VAI.

In summary, this study highlights the significant risk of posterior circulation stroke in patients with SCI. Given the difficulty of detecting such strokes in this population group, clinicians must maintain a high degree of vigilance for this condition.

\section{DATA ARCHIVING}

There were no data to deposit.

\section{CONFLICT OF INTEREST}

The authors declare no conflict of interest.

\section{ACKNOWLEDGEMENTS}

We wish to thank Ms. Deborah King for the valuable help and advice on study design and excellent technical assistance. This work was supported by the UK Spinal Cord Injury Network (grant no. SCI18).

1 BiffI WL, Moore EE, Elliott JP, Ray C, Offner PJ, Franciose RJ et al. The devastating potential of blunt vertebral arterial injuries. Ann Surg 2000; 231: 672-681.

2 Mueller CA, Peters I, Podlogar M, Kovacs A, Urbach H, Schaller K et al. Vertebral artery injuries following cervical spine trauma: a prospective observational study. Eur Spine $J$ 2011; 20: 2202-2209.
3 Torina PJ, Flanders AE, Carrino JA, Burns AS, Friedman DP, Harrop JS et al. Incidence of vertebral artery thrombosis in cervical spine trauma: correlation with severity of spinal cord injury. AJNR Am J Neuroradiol [Comparative StudyResearch Support, US Gov't, Non-P.H.S.] 2005; 26: 2645-2651.

4 Taneichi H, Suda K, Kajino T, Kaneda K. Traumatically induced vertebral artery occlusion associated with cervical spine injuries: prospective study using magnetic resonance angiography. Spine 2005; 30: 1955-1962.

5 Miller PR, Fabian TC, Bee TK, Timmons S, Chamsuddin A, Finkle R et al. Blunt cerebrovascular injuries: diagnosis and treatment. J Trauma 2001; 51: 279-285; discussion 85-6.

6 Zavala-Alarcon E, Emmans L, Little R, Bant A. Percutaneous intervention for posterior fossa ischemia. A single center experience and review of the literature. Intl J Cardiol [Review] 2008; 127: 70-77.

7 Friedman D, Flanders A, Thomas C, Millar W. Vertebral artery injury after acute cervical spine trauma: rate of occurrence as detected by MR angiography and assessment of clinical consequences. AJR Am J Roentgenol 1995; 164: 443-447; discussion 8-9.

8 Quint DJ, Spickler EM. Magnetic resonance demonstration of vertebral artery dissection. Report of two cases. J Neurosurg 1990; 72: 964-967.

9 Weller SJ, Rossitch Jr E, Malek AM. Detection of vertebral artery injury after cervical spine trauma using magnetic resonance angiography. J Trauma [Case ReportsReview]. 1999; 46: 660-666.

10 Eberhardt O, Naegele T, Raygrotzki S, Weller M, Ernemann U. Stenting of vertebrobasilar arteries in symptomatic atherosclerotic disease and acute occlusion: case series and review of the literature. J Vasc Surg [Case ReportsReview] 2006; 43: 11451154

11 Vernooij MW, Ikram MA, Tanghe HL, Vincent AJ, Hofman A, Krestin GP et al. Incidental findings on brain MRI in the general population. N Engl J Med [Research Support, NonU.S. Gov't] 2007; 357: 1821-1828.

12 Boon A, Lodder J, Heuts-van Raak L, Kessels F. Silent brain infarcts in 755 consecutive patients with a first-ever supratentorial ischemic stroke. Relationship with index-stroke subtype, vascular risk factors, and mortality. Stroke 1994; 25: 2384-2390

13 Compter A, van der Worp HB, Algra A, Kappelle LJ. Prevalence and prognosis of asymptomatic vertebral artery origin stenosis in patients with clinically manifest arterial disease. Stroke [Research Support, Non-US Govt] 2011; 42: 2795-2800.

14 McCormick MT, Robinson HK, Bone I, McLean AN, Allan DB. Blunt cervical spine trauma as a cause of spinal cord injury and delayed cortical blindness. Spinal Cord [Case Reports] 2007; 45: 687-689.

15 Miller PR, Fabian TC, Croce MA, Cagiannos C, Williams JS, Vang M et al. Prospective screening for blunt cerebrovascular injuries: analysis of diagnostic modalities and outcomes. Ann Surg [Comparative Study] 2002; 236: 386-393.

16 Wei CW, Montanera W, Selchen D, Lian J, Stevens C, de Tilly LN. Blunt cerebrovascular injuries: diagnosis and management outcomes. Can J Neurol Sci 2010; 37: 574-579.

17 Biffl WL, Ray Jr CE, Moore EE, Franciose RJ, Aly S, Heyrosa MG et al. Treatmentrelated outcomes from blunt cerebrovascular injuries: importance of routine follow-up arteriography. Ann Surg 2002; 235: 699-706.

18 Park JH, Kim JM, Roh JK. Hypoplastic vertebral artery: frequency and associations with ischaemic stroke territory. J Neurol Neurosurg Psychiatry 2007; 78: 954-958.

19 Biffl WL, Moore EE, Offner PJ, Brega KE, Franciose RJ, Burch JM. Blunt carotid arterial injuries: implications of a new grading scale. J Trauma 1999; 47: 845-853.

20 Harrigan MR, Weinberg JA, Peaks YS, Taylor SM, Cava LP, Richman J et al. Management of blunt extracranial traumatic cerebrovascular injury: a multidisciplinary survey of current practice. World J Emerg Surg 2011; 6: 11.

21 Katzman GL, Dagher AP, Patronas NJ. Incidental findings on brain magnetic resonance imaging from 1000 asymptomatic volunteers. JAMA 1999; 282: 36-39. 